\title{
Butterfly: Resisting the harms of anti- trafficking policies and fostering peer-based organising in Canada
}

\author{
Elene Lam and Annalee Lepp
}

\begin{abstract}
Drawing on knowledge gleaned from over four years of community organising and from the ongoing compilation of the experiences of Asian and migrant sex workers in Canada, this article presents a case study of the work of Butterfly, a migrant sex worker-led and sex worker-focused organisation. It explores how Butterfly, through various mediums, has sought to challenge the discourses, laws, and policies that negatively impact Asian and migrant sex workers. It also highlights how the organisation, through its peer-based model and activities and its radical centring of the voices and experiences of Asian and migrant sex workers, is able to more effectively address their everyday realities and struggles. In this way, Butterfly offers a grassroots alternative to the often detrimental prohibitionist and anti-trafficking interventions undertaken by governments, law enforcement, and social service organisations.
\end{abstract}

Keywords: migrant sex work, racial profiling, human trafficking, peer-based organising, Canada

Suggested citation: E Lam and A Lepp, 'Butterfly: Resisting the harms of anti-trafficking policies and fostering peer-based organising in Canada', AntiTrafficking Review, issue 12, 2019, pp. 91-107, www.antitraffickingreview.org

\section{Introduction}

Established in 2014, Butterfly (Asian and Migrant Sex Workers Support Network) is a grassroots organisation that works directly with, and is led by, Asian and migrant sex workers in Toronto and other Canadian cities. Since its inception, Butterfly has filled a significant gap in the realm of sex worker organising in Canada, especially by enabling migrant sex workers to create a 
strong and empowering mutual support network, to build capacity and foster leadership, and to advocate for their legal, labour, and social rights. ${ }^{1}$ This is especially important because they face various and significant obstacles, including language barriers, im/migration status, social marginalisation, and exclusionary practices that inhibit them from accessing and participating in the sex worker rights movement in Canada. ${ }^{2}$ Thus, Butterfly contributes an important intersectional perspective to the sex worker movement, which is grounded in an understanding of the issues faced by Asian and migrant sex workers, including racism, classism, and xenophobia, and the need to build strong alliances among the sex worker, labour, migrant, and racial justice movements.

Drawing on the grassroots knowledge gleaned from over four years of community organising and from the ongoing compilation of the stories of Asian and migrant sex workers' experiences, this article presents a case study of the work of Butterfly. It documents how the organisation has sought to challenge the discourses and policies that directly and negatively impact Asian and migrant sex workers in the Canadian context. These efforts have involved initiatives to resist oppressive immigration, criminal, and municipal laws and policies, to expose the harmful effects of anti-trafficking interventions, and to raise broad awareness about Asian and migrant sex workers' experiences and needs, including among social service organisations. The article also highlights how Butterfly, through its peer-based model and activities, is able to more effectively address the everyday realities and struggles of Asian and migrant sex workers, thereby offering a radical grassroots alternative to the often detrimental government- and social service organisation-sponsored prohibitionist and anti-trafficking interventions.

The other sex worker organisation in Canada that works specifically with newcomer, migrant, and immigrant women (cisgender, trans, and gender-diverse) engaged in indoor sex work is Supporting Women's Alternatives Network (SWAN) in Vancouver, British Columbia. See http://swanvancouver.ca.

2 E Lam, 'The Birth of Butterfly: Bringing migrant sex workers' voices into the sex workers' rights movement', Research for Sex Work, issue 15, 2016, pp. 1-4, http://www.nswp.org/resource/the-birth-butterly-bringing-migrant-sexworkers-voices-the-sex-workers-rights-movement; E Lam and C Gallant, 'Migrant Sex Workers' Justice: Building alliances across movements' in E M Durisin, E van der Meulen and C Bruckert (eds.), Red Light Labour: Sex work regulation, agency, and resistance, University of British Columbia Press, Vancouver, 2018, pp. 293-304. 


\section{Sex Work and Trafficking in Canada}

In December 2014, the then Conservative government enacted the Protection of Communities and Exploited Persons Act (PCEPA), ${ }^{3}$ the 'made in Canada' end demand regime. Previously conceived as a 'public nuisance', prostitution was redefined under PCEPA as 'sexual exploitation', where all sex workers are deemed to be victims. The laws criminalise clients and third parties, communication in specific public places, working with others, and advertising sexual services, with the main objective being to eradicate prostitution. ${ }^{4}$ Three years after the laws were enacted, based on sex workers' reports across the country, the Canadian Alliance for Sex Work Law Reform confirmed PCEPA's endangering effects, with Indigenous, transgender, racialised, and im/migrant sex workers as the most negatively impacted. The laws have continued and intensified the displacement and isolation of sex workers; increased targeted violence, stigma, and discrimination against them; and enhanced police profiling and surveillance. ${ }^{5}$

Canada's Immigration and Refugee Protection Act (2002) criminalises human trafficking and people smuggling, and anti-trafficking provisions were introduced into the Criminal Code in 2005. In 2012, the same Conservative

3 Department of Justice Canada, Technical Paper: Bill C-36, An Act to amend the Criminal Code in response to the Supreme Course of Canada decision in Attorney General of Canada v. Bedford and to make consequential amendments to other Acts (Protection of Communities and Exploited Persons Act), 1 December 2014, http:// www.justice.gc.ca/eng/rp-pr/other-autre/protect/index.html.

4 According to the Department of Justice, 'Bill C-36 harmonize[d] the penalties imposed for human trafficking and prostitution-related conduct to ensure a consistent response to practices that are linked'. See: Department of Justice Canada, 'Prostitution Criminal Law Reform: Bill C-36, the Protection of Communities and Exploited Persons Act, 18 March 2015, http://www.justice.gc.ca/eng/rp$\mathrm{pr} /$ other-autre/c36fs_fi.

5 Canadian Alliance for Sex Work Law Reform, Safety, Dignity, Equality: Recommendations for sex work law reform in Canada, March 2017, p. 7. Over the course of their historical development within a white settler colony, Canada's prostitution laws and their implementation were and continue to be especially harmful to Indigenous, racialised, and migrant sex workers. See, for example: N Sayers, 'Canada's Anti-Prostitution Laws: A method for social control', kwetoday, 28 December 2013, https://kwetoday.com/2013/12/28/canadas-antiprostitution-laws-a-method-for-social-control; C B Backhouse, 'NineteenthCentury Canadian Prostitution Law: Reflection of a discriminatory society', Histoire sociale/Social History, vol. 18, no. 36, 1985, pp. 387-423; R Maynard, 'Do Black Sex Workers' Lives Matter? Whitewashed anti-slavery, racial justice, and abolition', in Durisin, van der Meulen and Bruckert, pp. 281-292; B Belak and D Bennett, Evaluating Canada's Sex Work Laws: The case for repeal, Pivot Legal Society, Vancouver, 2016, http://www.pivotlegal.org/evaluating_canada_s_sex_ work_laws_the_case_for_repeal. 
government, as both an anti-trafficking protection and an anti-sex work border control measure, closed down the temporary exotic dancers' visa (which had been available since the 1960s) and barred all sex work-related businesses from accessing the temporary foreign worker programme. Furthermore, any migrant workers who are issued open work permits (including international students, refugee claimants, or individuals under sponsorship) are now restricted from working in the commercial sex sector. ${ }^{6}$ In the latter case, migrants risk having their work permits and immigration status revoked and being deported if they work in sex-related businesses, including legally-operating and licensed massage and body rub parlours, strip clubs, and escort agencies. ${ }^{7}$

At the more local level, while, in theory, municipal bylaws cannot directly prohibit the sale of sexual services, they have also been used as a repressive mechanism to target, regulate, investigate, and shut down businesses perceived to be potential venues for trafficking and, in particular, establishments where Asian im/migrant women work. ${ }^{8}$ In December 2013, the Toronto City Council, in 'condemning the horrific crime of human trafficking', passed a motion entitled 'Initiatives to Address Human Trafficking' that approved 'the review of licensing by-laws concerning trades and businesses that are known to be destinations for human trafficking." It also called for a report to be compiled that would address human trafficking and 'a strategy to more vigorously prosecute charges related to municipal by-law infractions by the adult

6 Government of Canada, Immigration and Refugee Protection Act, Immigration and Refugee Protection Regulations, SOR/2002-227 s. 183(1)(b.1). See also E M Durisin and R Heynen, 'Producing the "Trafficked Woman": Canadian newspaper reporting on Eastern European exotic dancers during the 1990s', Atlantis: Critical Studies in Gender, Culture and Social Justice, vol. 37, no. 2, 2015/2016, pp. 8-24; T Law, 'Cashing in on Cachet? Ethnicity and gender in the strip club', Canadian Journal of Women and the Law, vol. 24, no. 1, 2012, pp. 147-152, https://doi.org/ 10.3138/cjwl.24.1.135; T Law, 'Licensed or Licentious?: Examining the regulatory discussions of stripping in Ontario', Canadian Journal of Law and Society, vol. 30, no. 1, 2015, pp. 31-50, https://doi.org/10.1017/cls.2014.25.

7 Canadian Alliance for Sex Work Law Reform, 'Sex Workers Speak Out: Migrant sex workers live under constant police threat', Ricochet, 23 September 2016, https://ricochet.media/en/1421/migrant-sex-workers-live-under-constantpolice-threat.

8 T Santini and E Lam, 'Upholding and Promoting Human Rights, Justice and Access for Migrant Sex Workers. Part 2 - Laws affecting migrant sex workers. Municipal law and migrant sex workers' rights', October 2017, https:// docs.wixstatic.com/ugd/5bd754_c5dcee7f55114eaf82ba5ddee244fb68.pdf; Canadian Women's Foundation, 'No More': Ending sex-trafficking in Canada. Report of the National Task Force on Sex Trafficking of Women and Girls in Canada, Toronto, 2014, p. 66.

9 City of Toronto, 'EX 36.13 Initiatives to Address Human Trafficking', End Trafficking TO, 16-18 December 2013, https://www.toronto.ca/citygovernment/accountability-operations-customer-service/long-term-vision-plansand-strategies/end-trafficking-to. 
entertainment, body-rub, and holistic licence classes. ${ }^{, 10}$ In October 2017, a report submitted to the Toronto City Council sounded the alarm that 25 per cent of the 410 holistic centres in Toronto 'appeared to be offering services outside their licensing parameters and conditions. These centres advertised with sexually explicit photographs and had suggestive descriptions of services such as erotic massage ... [T] hese centres could potentially pose an array of health, safety and community issues, including the risk of human trafficking. ${ }^{, 1}$ As Butterfly's research on this sector found, the number of by-law inspections of holistic centres in Toronto increased by 212 per cent (from 569 in 2013 to 1,780 in 2016) and those of holistic practitioners ${ }^{12}$ by 323 per cent (from 611 in 2013 to 2,585 in 2016), which together constituted about 20 per cent of all bylaw investigations in the city. ${ }^{13}$ The majority of workers being targeted, whether they provide sexual services or not, are racialised and especially Asian women (migrants, refugees, or citizens) who speak little or no English.

As sex worker rights activists and their allies have consistently argued, human trafficking - in conjunction with national security, moral values, and protection of the vulnerable- - has been deployed to legitimise the criminalisation of sex work, stringent migration policies, heightened border surveillance, racial profiling, and repressive enforcement raids and investigations of indoor sex work and other establishments. ${ }^{14}$ Despite the intensified focus on domestic

${ }^{10}$ C Howorun, '25 per cent of Toronto holistic centres offer sexual services: report', CityNews, 26 October 2017, https://toronto.citynews.ca/2017/10/26/25per-cent-toronto-holistic-centres-offer-sexual-services-report. According to Santini and Lam, 'common municipal offences include touching prohibited body areas (e.g. breasts, genitals), being undressed in the workplace, locking/unlocking the door to the room in which the services are performed, or being open to the public beyond legally permitted hours of operation.' Santini and Lam, p. 3.

${ }^{11}$ City of Toronto, Auditor General, 'A Review of the Municipal Licensing and Standards Division's Management of Business Licenses - Part Two: Licensed Holistic Centres', 24 October 2017, https://www.toronto.ca/city-government/ accountability-operations-customer-service/accountability-officers / auditor-general/reports/auditor-generals-reports/a-review-of-municipallicensing-and-standards-divisions-management-of-business-licences-part-twolicensed-holistic-centres.

12 Holistic practitioners provide services such as reiki, aromatherapy, and massage therapy in spas, wellness centres, or massage parlours.

13 E Lam, Survey of Toronto Holistic Practitioners' Experiences with Bylaw Enforcement and Police, Butterfly, Toronto, 2018, p. 13.

${ }^{14}$ See, for example, K Kempadoo and N McFadyen (eds.), Challenging Trafficking in Canada: Policy brief, Centre for Feminist Research, York University, Toronto, July 2017; R Maynard, 'Fighting Wrongs with Wrongs? How Canadian anti-trafficking crusades have failed sex workers, migrants, and Indigenous communities', Atlantis: Critical Studies in Gender, Culture and Social Justice, vol. 37, no. 2, 2015, pp. 40-56; A Lepp, 'Canada', in Global Alliance Against Traffic in Women, Sex Workers Organising for Change: Self-representation, community mobilisation, and working conditions, GAATW, Bangkok, 2018, pp. 150-195; J Kaye, Responding to Human Trafficking: Dispossession, colonial violence, and resistance among Indigenous and racialized women, University of Toronto Press, Toronto, 2017. 
trafficking in Canada over the last decade, especially as it affects Indigenous women and girls as well as minors, Asian and migrant sex workers have been consistent targets of anti-trafficking campaigns and interventions conducted by Canadian law enforcement and non-governmental organisations since the 1990s. ${ }^{15}$ In the current anti-sex work, anti-migration, and racist environment, in which federal, provincial, and municipal governments are investing millions of dollars in anti-trafficking enforcement and other efforts, ${ }^{16}$ Asian and migrant sex workers continue to be marginalised and silenced. This has resulted in the ongoing erasure of the diversity and complexity of their experiences and in the perpetuation of the notion that they are particularly 'at risk' of being trafficked.

\section{Migrant Sex Workers, Holistic Practitioners, and Anti- Trafficking Interventions}

Butterfly works with Asian and migrant sex workers of any gender (but primarily women) who have different immigration statuses (including permanent residents, international students, tourists, refugees, and people with no legal status) and who mainly work at apartments, hotels, escort agencies, massage parlours, and holistic centres in Toronto and other cities. Like other workers who participate in transnational flows of labour, Asian and migrant sex workers make the decision to work in the sex industry in Canada for a variety of reasons: to meet their basic needs, to attain economic security and advancement, to move away from oppressive circumstances (e.g. low-wage work in other sectors, domestic violence, etc.), to support their families and finance the education of their children, to achieve self-actualisation, and/or to pursue their dreams. As Laura Agustín has argued, migrants 'make decisions to change their lives by traveling abroad to work, weighing their options, talking with friends and family, taking advantage of opportunities offered, and continuing to exercise judgement along the way'; many are also 'actively engaged in using social networks to travel. ${ }^{17}$ Asian and migrant sex

15 A Lepp, "Collateral Damage": Anti-trafficking campaigns, border security, and sex workers' rights struggles in Canada', in P Gentile, G Kinsman, and L P Rankin (eds.), We Still Demand! Redefining resistance in sex and gender struggles, University of British Columbia Press, Vancouver, 2017, pp. 222-249.

16 Government of Canada, National Action Plan to Combat Human Trafficking, Her Majesty the Queen in Right of Canada, Ottawa, 2012, p. 10; T Grant, 'Ontario unveils \$72-million plan to fight human trafficking', The Globe and Mail, 30 June 2016, https://www.theglobeandmail.com/news/national/canada-continues-tobe-a-source-for-sex-trafficking-annual-report/article30700484.

17 L Agustín, 'Migrants in the Mistress's House: Other voices in the "trafficking" debate', Social Politics: International Studies in Gender, State and Society, vol. 12, no. 1, 2005, pp. 97-98, https://doi.org/10.1093/sp/jxi003. 
workers' decisions may also be shaped by other factors, such as their inability to find other work due to their im/migration status and language barriers as well as racism and discrimination in the labour market, or because the educational credentials or work experiences they obtained outside of Canada are not recognised in the country. As a result, the sex industry may be the best or one of the few labour options available to members of racialised and marginalised communities.

As in other under-regulated informal labour sectors, Asian and migrant sex workers may face various issues in their workplaces, including substandard or exploitative working conditions. For example, as Butterfly has found through its work, managers may take advantage of migrant sex workers' social isolation or precarious/undocumented status by, for instance, holding their passports, not paying them, imposing unreasonable charges, or pressuring them to work long hours. Their precarious immigration status compounded by the stigmatisation and criminalisation of sex work, racial profiling and discrimination, as well as surveillance and over-policing contribute to their vulnerability to various forms of violence, oppression, and exploitation at the hands of other actors, such as intimate partners, clients, police, and other law enforcement agencies.

Since the 1990s, as noted above, Asian and migrant sex workers have been a consistent focus of anti-trafficking interventions in Canada. The imposed label of being 'at risk' of trafficking is premised on longstanding racialised and gendered assumptions about Asian and migrant sex workers as passive and powerless, as controlled and exploited by foreign traffickers and transnational crime rings, as unable to grasp their victimised situation or speak for themselves, and as in need of rescue. ${ }^{18}$ Such assumptions have significantly shaped the lists of indicators and 'red flags' developed by Canadian law enforcement agencies and social service organisations, which are used in human trafficking awareness and training programmes and are meant to assist in identifying potential 'victims.' As SWAN Vancouver has pointed out, 'it is not always the red flag itself that indicates risk but who it is applied to. For example, when a number of non-White, and especially Asian, sex workers who speak

${ }^{18}$ Lam and Gallant, p. 296. See also LA Jeffrey, 'Canada and Migrant Sex Work: Challenging the "foreign" in foreign policy', Canadian Foreign Policy Journal, vol. 12, no. 1, 2005, pp. 33-48, https://doi.org/10.1080/11926422.2005.9673387; K Kempadoo, 'The Modern-Day White (Wo)Man's Burden: Trends in antitrafficking and anti-slavery campaigns', Journal of Human Trafficking, vol. 1, no. 1, 2015, pp. 8-20, https://doi.org/10.1080/23322705.2015.1006120. 
accented English work together, this work situation may be perceived as a case of trafficking whereas the same conclusion may not be drawn from a group of White, Canadian-born sex workers. ${ }^{19}$

In addition to the 'red flags' being 'vague' and 'overbroad', ${ }^{20}$ they are also used as a pretext for increasing the social surveillance and law enforcement investigations of Asian and migrant sex workers and their workplaces. Since 2015, for example, law enforcement agencies across Canada, often in collaboration with social service organisations, have participated in seven waves of what is known as Operation Northern Spotlight. ${ }^{21}$ During these operations, the typical scenario is that 'police officers posing as clients set up dates online with sex workers, through websites like Craigslist and Backpage, then surprise them in hotel rooms" or they conduct "shock and awe" raids on indoor sex work venues. ${ }^{22}$ According to the Canadian Alliance for Sex Work Law Reform, 'by casting a wide net, police involved in Operation Northern Spotlight have approached, detained, and harassed numerous sex workers where there has been no evidence of coercion, exploitation, or human trafficking. ${ }^{23}$ In addition, Operation Northern Spotlight has generated the intensified racial profiling, surveillance, and targeting of Asian sex workers, including those who are permanent residents or Canadian citizens.

19 SWAN Vancouver compiled a list of 'red flags' included in popular human trafficking toolkits. In addition to 'indoor sex venue mainly has women of the same nationality working there', other indicators include 'distrust/fear of authority', 'fear of revealing immigration status', 'does not speak English/French and/or experiences language barriers', 'allowing others to speak on one's behalf, even when directly addressed', 'working excessively long hours', 'no access to medical care', and 'fee for transport and living quarters arranged for in country of destination.' See: SWAN Vancouver, Im/migrant Sex Workers, Myths and Misconceptions: Realities of the anti-trafficked, SWAN Vancouver Society, Vancouver, 2015, pp. 15-16, http://swanvancouver.ca/wp-content/uploads/2014/01/ Realities-of-the-Anti-Trafficked.pdf.

20 Canada, House of Commons, Standing Committee on Justice and Human Rights, Moving Forward in the Fight Against Human Trafficking in Canada, $42^{\text {nd }}$ Parliament, $1^{\text {st }}$ Session, Ottawa, 2018, p. 37, http://www.ourcommons.ca/Content/ Committee/421/JUST/Reports/RP10243099/justrp24/justrp24-e.pdf.

21 Royal Canadian Mounted Police, 'Operation Northern Spotlight VII: Canadian Police Services continue to work together to stop human trafficking', 24 October 2018, http://www.rcmp-grc.gc.ca/en/news/2018/operation-northernspotlight-vii-canadian-police-services-continue-work-together-stop.

22 SWAN Vancouver, 'Open Letter to BC Law Enforcement Calling for NonParticipation in Operation Northern Spotlight', 6 July 2017, http:// swanvancouver.ca/operation-northern-spotlight.

${ }^{23}$ Canadian Alliance for Sex Work Law Reform, 'Sex Workers Rights Groups Oppose Police Operation Northern Spotlight. Press Release', 9 October 2018, http://www.spoc.ca/ONS\%20press\%20release.pdf. 


\section{Behind the Rescue}

Through its organising work and the compilation of first-person narratives, Butterfly has documented the effects of such law enforcement operations on Asian and migrant sex workers. For example, the testimonies of eighteen sex workers with varied immigration statuses ${ }^{24}$ who contacted the organisation between May 2015 and August 2016 are revealing. Many of the women indicated that the first question law enforcement asked upon entering, usually without warning, their apartments, hotel rooms, or indoor workplaces was whether they were being coerced; as Sun recounted, one of the police officers who rushed into her apartment asked: 'Are you under the control of anyone? Is anyone forcing you to do this? Who is your boss? ${ }^{25}$ When they responded that they were working voluntarily, the anti-trafficking intervention quickly turned into protracted investigations into their immigration status and whether they were working illegally in the sex industry; this meant that Canada Border Services Agency (CBSA) was immediately contacted and became directly involved.

All of the eighteen women who supplied testimonies were arrested, interrogated, and detained for up to three months in police stations, immigration centres, or prisons. As they recounted, police and CBSA officers used threats, intimidation, false information, and fabrication of evidence to extract information from them or to force them to admit to working illegally in Canada. If the women collaborated with or were in any way assisted or supported by co-workers, friends, and acquaintances (such as supplying accommodation, helping with money transfers or advertising, or using a friend's credit card to book a hotel room), law enforcement read these activities as evidence of involvement in trafficking or organised crime. These suspicions would trigger broader criminal and immigration investigations, including surveillance of their online footprint, which focused on members of the women's social networks, and authorities used such associations as evidence of an 'ongoing risk' and as justification for continuing to hold them in detention as a protective measure. ${ }^{26}$

${ }^{24}$ According to Butterfly, 'three of these individuals had working permits under sponsorship, one had a student visa and working permit and eight had valid visitor visas. The other six had lost their official permission to be in Canada, through the loss of refugee status or sponsorship'. E Lam, Behind the Rescue: How anti-trafficking investigations and policies harm migrant sex workers, Butterfly, Toronto, April 2018, p. 4, https://docs.wixstatic.com/ugd/5bd754_bbd71c0235c740 e3a7d444956d95236b.pdf.

25 'Sun's Story', Ibid., p. 7.

26 'Victimization Created by Anti-Trafficking Investigations: Anti-trafficking as anti-sex work \& anti-migration enforcement', Ibid., p. 27. 
While in detention, the women who could not speak English and who had no access to interpretation, indicated that they felt very isolated and afraid. They also described their experiences of degrading, cruel, and inhumane treatment at the hands of authorities, which included being restrained, not being permitted to contact friends or family, not being allowed to sleep, and being strip searched. Mi indicated that 'I was locked with chains and weights, on my wrists, waist and legs ... I felt like I was being treated as a murder suspect. They did not allow me to make a phone call or contact other people. ${ }^{27}$ Cookie shared that, while in detention for thirty-five days, much of which was spent in solitary confinement because authorities feared that she might commit suicide, 'I was strip searched five times. Throughout this entire process, I felt like less of a person, and I lost a part of my humanity. ${ }^{28}$ None of the women was told how long they would be detained. Chen Chen indicated that 'I have written a letter to my son, but I cannot give it to him. Please give it to him after I die. I really cannot survive here; it is so horrible. No one can talk to me. I don't know how long I need to stay here. I believe I will die here. ${ }^{29}$ In five cases, the women also reported that their personal property-identity documents, valuables like jewellery, and their money (CAD 50,000, or approx. USD 32,000, in one case)-had been seized by law enforcement officers and never returned. ${ }^{30}$ All of the eighteen women were eventually deported.

Between October 2015 and August 2017, Butterfly, in collaboration with a number of other organisations, also conducted a survey of 61 registered Asian holistic practitioners ${ }^{31}$ working in Toronto who, as noted above, have become the target of increased municipal inspections, conducted by bylaw enforcement officers in collaboration with local police, over the last three years. These inspections are allegedly designed to promote workplace health and safety, but they are also a response to suspicions that holistic centres in Toronto offer sexual services and might be sites of human trafficking. Survey respondents did identify a range of workplace issues, including robbery or theft (36 per cent), physical or sexual assault at the hands of clients or others (19.7 per cent), and non-payment by clients or managers (23 per cent). The research, however, 'did not uncover any instances of forced labour or trafficking. ${ }^{32}$ Furthermore, the vast majority (93.1 per cent) of respondents indicated that they had not lodged complaints to police for these infractions,

\footnotetext{
'Mi's Story', Ibid., pp. 14, 29.

'Cookie's Story', Ibid., p. 22.

'Extracts From Stories of Other Migrant Sex Workers', Ibid., p. 24.

'Victimization Created by Anti-Trafficking Investigations', Ibid., pp. 30-31.

1 The survey respondents ranged in age between 24 and 64 years and had lived in Canada for between one and ten years. Lam, Survey on Toronto Holistic Practitioners, p. 9.

32 Ibid., p. 19.
} 
maintaining that they feared that doing so would trigger more inspections, cause the loss of clients or business, and/or would result in them being arrested, charged, fined, or discriminated against by law enforcement. Some also reported that they had had negative and unhelpful experiences with police when lodging such complaints. ${ }^{33}$ These responses are not surprising given that the majority of respondents (65.5 per cent) indicated that their primary workplace concern was the number and frequency of bylaw inspections and/ or police raids given that half of them 'had been arrested, issued a ticket, or received a fine. ${ }^{34}$ Of equal significance, 34.3 per cent reported being abused, harassed, and intimidated by bylaw enforcement and police officers during the often protracted inspections. These actions tended to involve threatening questions about their immigration status, unwarranted searches of their personal items, and, at times, highly stigmatising and dehumanising treatment. For example, in order to determine if they were providing erotic services, three respondents shared that they 'were asked to remove their robes or pull up their dresses to show their clothing and underwear, and two indicated that the officers took pictures of them in this state. ${ }^{35}$

Butterfly members are often asked if Asian holistic practitioners in Toronto are providing sex services. In response, they point out that it should not matter if they are sex workers or not but what does matter is that they are experiencing abuse and humiliation at the hands of bylaw officers and local police. They add that it is important to challenge the perception that, if the workers are engaging in sex work, then 'what law enforcement is doing is okay'. ${ }^{36}$ Furthermore, as of April 2018, according to Butterfly and the Coalition Against Abuse By Bylaw Enforcement, 'the city has dedicated $\$ 682,000$ of its annual budget to employ five additional bylaw enforcement officers to conduct these inspections', with a 'specific mandate of targeting 410 holistic centres and 25 body rub parlors', meaning 'victimization and humiliation will only escalate. ${ }^{37}$

33 Ibid., pp. 10-11.

34 Ibid., p. 10, 16.

35 Ibid., p. 16.

36 M Ramsawakh, 'We Need to Stop Confusing Sex Work with Human Trafficking', Medium, 29 August 2018, https://medium.com/shareyournuance/we-need-tostop-confusing-sex-work-with-human-trafficking-6ba7897fd3cd.

37 Butterfly, 'Toronto's Bylaw Officers are Leading a Racist Attack on Spa Workers', Medium, 23 April 2018, https://medium.com/@Butterflysw/torontos-bylawofficers-are-leading-a-racist-attack-on-spa-workers-385bb33f6fff; Coalition Against Abuse By Bylaw Enforcement, 'Protect the Human Rights of Holistic Practitioners - Stop Abuse by Bylaw Enforcement', Change.org, 2018, https:// www.change.org/p/coalition-against-abuse-by-bylaw-enforcement-protect-thehuman-rights-of-holistic-practitioners-stop-abuse-by-bylaw-enforcement. 


\section{Peer-Based Community Organising}

Butterfly recognises that Asian and migrant sex workers are experts of their own lives and seeks to empower them by offering a range of multi-language resources and information. For example, it maintains a 24/7 hotline in English, Mandarin, and Cantonese, provides crisis and counselling support, and engages in outreach work in venues where Asian and migrant sex workers work. The organisation has also created important opportunities for migrant sex workers' often silenced voices to be heard. In May 2015, Butterfly organised a community art project, entitled 'Butterfly Voices', which enabled Asian and migrant sex workers in Toronto and beyond to engage in 'the empowering acts of firstperson storytelling and art making' and to share their perspectives on their work, lives, and experiences. ${ }^{38}$ In turn, this project was exhibited at public venues in 2015 and 2016 in an effort to challenge stereotypical assumptions about Asian and migrant sex workers, to foster understanding of the diversity and complexities of their lives, and to cultivate greater respect for their agency. ${ }^{39}$

Core to Butterfly's philosophy and approach is to build a grassroots and peerbased organisational network through which Asian and migrant sex workers can reduce their social isolation, build community, and foster resilience. Rather than relying on the so-called protection of law enforcement or solely on outside service organisations, a peer-based model provides an important alternative, which allows Asian and migrant sex workers to build capacity, exchange knowledge, and create a network of mutual support. For example, they are able to share approaches to deal with bad bosses or clients, develop their own safety plans to avoid dangerous and abusive situations, devise strategies to use their collective bargaining power to negotiate better working conditions, reduce exploitation and violence, change workplaces or find a place to work, and secure clients and advertise within a criminalised environment. ${ }^{40}$

Butterfly has also produced accessible and multi-language publications and hosts workshops and trainings where Asian and migrant sex workers can gain an understanding of Canada's criminal, immigration, and municipal laws, and, depending on their im/migration status, how the laws may affect them and what their rights are. They also learn about and share strategies to minimise

38 E Lam (ed.), Journey of Butterflies 2016, April 2016, p. 8, https:// docs.wixstatic.com/ugd/5bd754_6d9ddaec30e947efbef4e94b7e7ee828.pdf.

39 For further information on this project, see Butterfly, 'Butterfly Voices: Collecting stories of migrant sex workers around the world', 2015, https:// docs.wixstatic.com/ugd/5bd754_f89a2fdcd4d648239f1a8992cb5cf82d.pdf; 'Migrant Sex Workers Art: Butterfly Voices', YouTube, 17 December 2016, https:/ /youtu.be/Z6g8xxUpCaw.

40 Lepp, 2018, p. 62. 
the harms and risks that they experience when they interact with authorities, be they city inspectors, municipal, provincial, or federal police officers, or immigration and CBSA officials. ${ }^{41}$ Through organising and fostering leadership in the migrant sex worker and other social justice movements, according to Butterfly, Asian and migrant sex workers are also better positioned to engage in advocacy work, challenge oppressive immigration and legal policies, and fight for safety, dignity, and justice.

By listening to and documenting the experiences of Asian and migrant sex workers, Butterfly's research offers further concrete evidence of the multiple harms of anti-trafficking investigations on these communities and exposes the manifold ways in which police, immigration, and bylaw enforcement officers abuse their power and violate the workers' human rights. As Butterfly has argued, racial profiling, intensified surveillance, and discriminatory treatment, as well as the persistent risk of arrest, detention, and deportation, contribute to the further marginalisation and isolation of sex workers and increase their mistrust of law enforcement, which in turn heightens their vulnerability to exploitation and violence. As the Canadian Alliance for Sex Work Law Reform reported in October 2018, 'In a survey of Asian sex workers in Toronto and Vancouver, 95 per cent indicated that they never seek help from law enforcement-even if they are experiencing violence, abuse, harassment or exploitation. ${ }^{42}$ Of equal significance, in early 2018, the Toronto City Council passed a motion to prohibit the members of the five largest professional holistic associations (representing 2,200 practitioners) from obtaining new licenses, a decision which disproportionately threatens the livelihoods of Asian $\mathrm{im} /$ migrant women, and especially those with limited English language skills. ${ }^{43}$

${ }^{41}$ See, for example, E Lam and T Santini, 'Upholding and Promoting Human Rights, Justice, and Access for Migrant Sex Workers: Part 3-Legal information for migrant sex workers', October 2017, https://docs.wixstatic.com/ugd/ 5bd754_506c23f7470e459f802c842381a1b1eb.pdf; Butterfly, 'Who is Who? Identifying law enforcers', July 2017, https://docs.wixstatic.com/ugd/ 5bd754_748f9f3d7c9a4139b999f5b4a26b9f7a.pdf.

42 Canadian Alliance for Sex Work Law Reform, 'Sex Workers Rights Groups Oppose Police Operation Northern Spotlight. Press Release', 9 October 2018, http://www.spoc.ca/ONS\%20press\%20release.pdf.

43 Butterfly, 'Toronto's Bylaw Officers Are Leading a Racist Attack on Spa Workers'. In March 2019, the Toronto City Council embarked on a series of public consultations and stakeholder meetings as part of its review of the bylaws governing body rub parlours and holistic practitioners. According to Butterfly, the intent behind the review is to ban or drastically reduce the number of licenses for holistic practitioners as an anti-trafficking measure, a move that is supported by prohibitionist groups in Toronto. Butterfly and its allies are lobbying the city council to adopt an evidence-based and labour rights approach, which includes ensuring the meaningful participation of the workers who will be directly affected. 
Butterfly constitutes one of the few sources of social and personal support for Asian and migrant sex workers, including those with precarious or no citizenship status who find themselves in forced labour situations or who are swept up in anti-trafficking investigations. For example, the organisation reported, with reference to the eighteen migrant sex workers discussed above, that it

sent 300 letters, emails, and phone messages to find social support for one of the women. Most of the social services organizations refused because she had not been officially identified as a trafficking victim and she was not a resident. Some service providers were also reluctant to offer support because they did not want to get involved in 'organized crime' when they found out the migrant sex worker was connected with other migrant sex workers. ${ }^{44}$

In addition to engaging in outreach work in hotels, massage parlours, holistic centres, and other establishments and to offering medical, emotional, personal, and emergency support to Asian and migrant sex workers, Butterfly members also provide them with various forms of direct assistance when, for example, they are arrested, detained, and deported:

We work quickly to find lawyers, access information regarding the case, advocate for workers every step of the way, and contact their friends and family. We visit and have phone calls with workers who are detained, as well as help them buy plane tickets to go back home [to minimize their time in detention], help them pack, and gather their personal items and valuables to bring to the airport or detention centre. We also accompany sex workers to court proceedings to provide support for them in the courtroom, represent them in detention review, help them find bond persons, and assist in finding community resources, such as shelter and social services. When sex workers are deported, we continue to support them even after deportation, helping them with housing, finances, coping with personal issues [including being traumatized during arrest and detention], and providing long-distance English classes when they return to their countries of origin. ${ }^{45}$

Butterfly is also committed to enhancing the social services that are available to Asian and migrant sex workers, especially given that, from its perspective, an increasing number of programmes are transforming themselves into prohibitionist-inspired anti-trafficking and sex worker exiting programmes.

\footnotetext{
44 Lam, Bebind the Rescue, p. 31.

45 Lam, Journey of Butterflies 2016, p. 7.
} 
Working in collaboration with a number of Toronto-based organisations (the Chinese Canadian National Council Toronto Chapter, the Chinese and Southeast Asian Legal Clinic, and St. Stephen's Community House), with the support of legal expert Tara Santini, and with the direct and meaningful participation of migrant sex workers, Butterfly has created a series of training materials and an online webinar specifically tailored for service providers and frontline workers. ${ }^{46}$ Taught from a sex worker, migrant, and labour rights perspective, the purposes of this training is to assist service providers to better understand the experiences and needs of migrant sex workers and how to protect and defend their labour and human rights. ${ }^{47}$ In addition, this educational work is designed to encourage service providers and frontline workers to develop a more critical perspective on mainstream anti-trafficking discourses and campaigns, including the tendency to conflate sex work, migration, and trafficking, and to understand their harmful effects on marginalised sex workers. Most concretely, service providers are also challenged to 'recognize that [their] own subjective values and ideologies associated with sex work and human trafficking may prevent [them] from understanding migrant sex workers' lived experiences, and from providing them with appropriate services and support. ${ }^{48}$ This reflective work is important so that frontline workers can incorporate human rights-based, person-centred, and non-judgemental approaches into their professional and service provision practices. As of 27 March 2018, over 350 service providers working in the legal, social work, sex work, and health sectors in Canada and other parts of the world have participated in the training either in-person or online, and over 1,200 individuals have accessed the training materials.

Finally, policy advocacy and alliance building with the full participation of Asian and migrant sex workers is also central to Butterfly's work. Whether preparing a submission to the House of Commons Standing Committee on Justice and Human Rights on Canada's federal human trafficking policy ${ }^{49}$ or

46 See, for example, T Santini and E Lam, 'Upholding and Promoting Human Rights, Justice and Access for Migrant Sex Workers. Part 1: Guide for service providers', October 2017; E Lam and V Wong, 'Supporting the Human Rights of Migrant Sex Workers: Legal training for services providers and front-line workers', YouTube, 22 January 2018, https://youtu.be/9PHfcSNjZV0. All of the training materials are available at https://www.butterflysw.org/legalinformation-for-services-prov.

47 Santini and Lam, 'Part 1: Guide for Service Providers', p. 3.

$48 \mathrm{~T}$ Santini and E Lam, 'Upholding and Promoting Human Rights, Justice and Access for Migrant Sex Workers. Part 4: Q \& A for service providers', October 2017, p. 8.

49 Butterfly, 'How Migrant Workers are Harmed by Anti-Trafficking Initiatives and Policies', Brief to the House of Commons Standing Committee on Justice and Human Rights, Human Trafficking in Canada, June 2018, https:// www.ourcommons.ca/Committees/en/JUST/StudyActivity?studyActivityId $=9749514$. 
appearing before the Municipal and Standards Committee of the City of Toronto on the issues of the over-policing of Asian holistic practitioners, ${ }^{50}$ it is essential that Asian and migrant sex workers are mobilised and supported in political lobbying and social justice work. Butterfly also works to build the migrant sex worker movement by fostering coalitions and alliances with a number of social justice groups, such as the Workers Action Centre, a Torontobased organisation fighting for fair and dignified work, especially for people in low-wage and unstable employment; the Migrant Workers Alliance for Change, a coalition of national migrant worker groups and their allies; as well as the FCJ Refugee Centre, the Chinese Canadian National Council Toronto Chapter, and other legal clinics. In order to strengthen the fight for Asian and migrant sex workers' rights, dignity, and justice, the organisation necessarily seeks to build connections among sex worker, labour, anti-racist, and migrant rights movements in Toronto and beyond.

\section{Conclusion}

As Elene Lam and Chanelle Gallant have argued, in recent decades,

sex workers have been pushing hard to have their voices heard in the media, in the academy, and in community spaces ... However, because of isolation, racism, language differences, and anti-immigrant xenophobia, migrant sex workers' voices are still missing from these conversations - both within the broader society and within the sex workers movement itself. This absence is exploited by anti-sex work prohibitionists who advocate for anti-trafficking measures that often work against the rights of sex workers and migrants. ${ }^{51}$

In its work, Butterfly has sought to radically centre the voices and experiences of Asian and migrant sex workers in Canada and to provide them with a multitude of relevant, accessible, and safe legal, social, and emergency supports so that they can better negotiate the conditions of their labour and their lives as both sex workers and as im/migrants. The organisation has also worked,

${ }^{50}$ Butterfly: Asian and Migrant Sex Workers Network, Maggie's: The Toronto Sex Workers Action Project, the Canadian Alliance for Sex Work Law Reform, the Canadian HIV/AIDS Legal Network, the Migrant Sex Work Project, Andrea Sterling, and Professor Emily van der Meulen, 'Submission to the City of Toronto, Licensing and Standards Committee, Regarding Pending Review of the BodyRub By-Law', 10 April 2018; AIDSLAW, 'Racism and Prejudice Have No Place in City Hall - A Message to Toronto City Council', Canadian HIV/AIDS Legal Network, 1 May 2018, http://www.aidslaw.ca/site/racism-and-prejudice-haveno-place-in-city-hall-a-message-to-toronto-city-council.

51 Lam and Gallant, p. 293. 
through various mediums, to expose the racist, anti-sex work, and antimigration logics of the anti-trafficking machinery. By mobilising Asian and migrant sex workers, Butterfly presents a meaningful and effective peer-based alternative to the punitive anti-trafficking law enforcement and rescue models. It focuses on prioritising connection, mutual support, and leadership, so that Asian and migrant sex workers can address the real issues they are experiencing, assist in actual cases of exploitation, abuse, and trafficking, increase their power and control over their work situations, and enhance their safety. Butterfly has also contributed a critical intersectional perspective to the sex worker movement and to other social movements committed to gender, labour, migrant, and racial justice.

Elene Lam is the founder and executive director of Butterfly (Asian and Migrant Sex Workers Support Network) and a co-founder of the Migrant Sex Workers Project. She has been involved in movements that focus on sex work, migration, gender, labour, and human rights for more than fifteen years in Asia and Canada. She advocates for the human rights of sex workers, the decriminalisation of sex work, and for reducing the harms of anti-trafficking interventions. Email: elenelam2020@gmail.com

Annalee Lepp is Associate Professor in the Department of Gender Studies at the University of Victoria, Canada. She is a founding member of the Global Alliance Against Traffic in Women (GAATW) Canada, which was established in 1996, and is a member of GAATW's Board of Directors. Since 1997, she has been involved in various collaborative research projects that examine Canadian state policies and practices as they relate to trafficking in persons and irregular cross-border movements as well as the impact of anti-trafficking policies on sex workers' rights in Canada. Email: alepp@uvic.ca 